\title{
Notas sobre religiosidad turdetana. Los depósitos sagrados del oppidum de Alhonoz (Herrera, Sevilla)
}

\author{
María BELÉN \\ Universidad de Sevilla
}

\begin{abstract}
Resumen
Durante los trabajos arqueológicos de 1977 en el oppidum de Alhonoz se hallaron una gran colección de cerámica y otras piezas poco comunes que constituyen una importante fuente documental para el estudio de la religiosidad turdetana. Hoy se acepta de forma unánime que estos materiales eran exvotos y ofrendas amortizados en la favissa de un santuario próximo, todavía no descubierto. Tras analizar los contextos arqueológicos en que se hallaron, proponemos datar los depósitos de Alhonoz en un momento avanzado del siglo II a.C. El clima de inseguridad que se vivía en la zona o la inminencia de algún episodio bélico, pudieron forzar la ocultación ritual de los objetos sagrados. El lenguaje simbólico de signo púnico con el que se expresa el culto a una divinidad femenina protectora de la comunidad, traduce un ambiente de fuerte interacción cultural en el interior de la región que los romanos llamaron Turdetania.
\end{abstract}

Palabras clave: Turdetania, Alhonoz, Favissa, Culto, Ritual.

\section{Summary}

In 1977, during the archaelogical excavations of the Alhonoz's oppidum, a huge collection of pottery and other unusual pieces were found. This collection is an important source of information for the study of Turdetanian religiousness. Today, it is solidly accepted that these materials were ex-vota objects and offerings kept in the favissa of a nearby sanctuary, yet undiscovered. After studying their archaeological context, our proposal is to date the Alhonoz's deposits in the late 2 nd century BC. Ritual hiding of these sacred objects may have been motivated by the insecurity existing around the area or the danger of imminent war. The symbolic language present in the worship of a female divinity who protected the community has a clear Punic component. This is to be seen as a sign of the strong cultural interaction on the region called Turdetania by the Romans.

Keywords: Turdetania, Alhonoz, Favissa, Cult, Ritual.

Las ruinas del oppidum de Alhonoz ocupan varios cerros contiguos que se elevan junto a la orilla izquierda del río Genil, entre los términos de Écija y Herrera, en el límite suroriental de la provincia de Sevilla con la de Córdoba (Fig. 1). Diversas campañas de excavación realizadas por

1 Facultad de Geografía e Historia, Departamento de Prehistoria y Arqueología. E-mail belendeamos@us.es. El trabajo se ha realizado en el marco del grupo HUM-650 del Plan Andaluz de Investigación y del proyecto "Religio
A. López Palomo en los años setenta y principios de los ochenta del siglo XX, permitieron comprobar que el hábitat protohistórico se fundó hacia el s. IX a C. y prolongó su existencia a lo largo del I milenio a.C. Durante el s. VIII llegaron desde la costa novedades arquitectónicas y producciones

Phoenicia Occidentalis: cultos fenicio-púnicos en el Extremo Occidente" (HAR2011-27257), cofinanciado por el Ministerio de Ciencia e Innovación de España y los Fondos Europeos de Desarrollo Regional. 


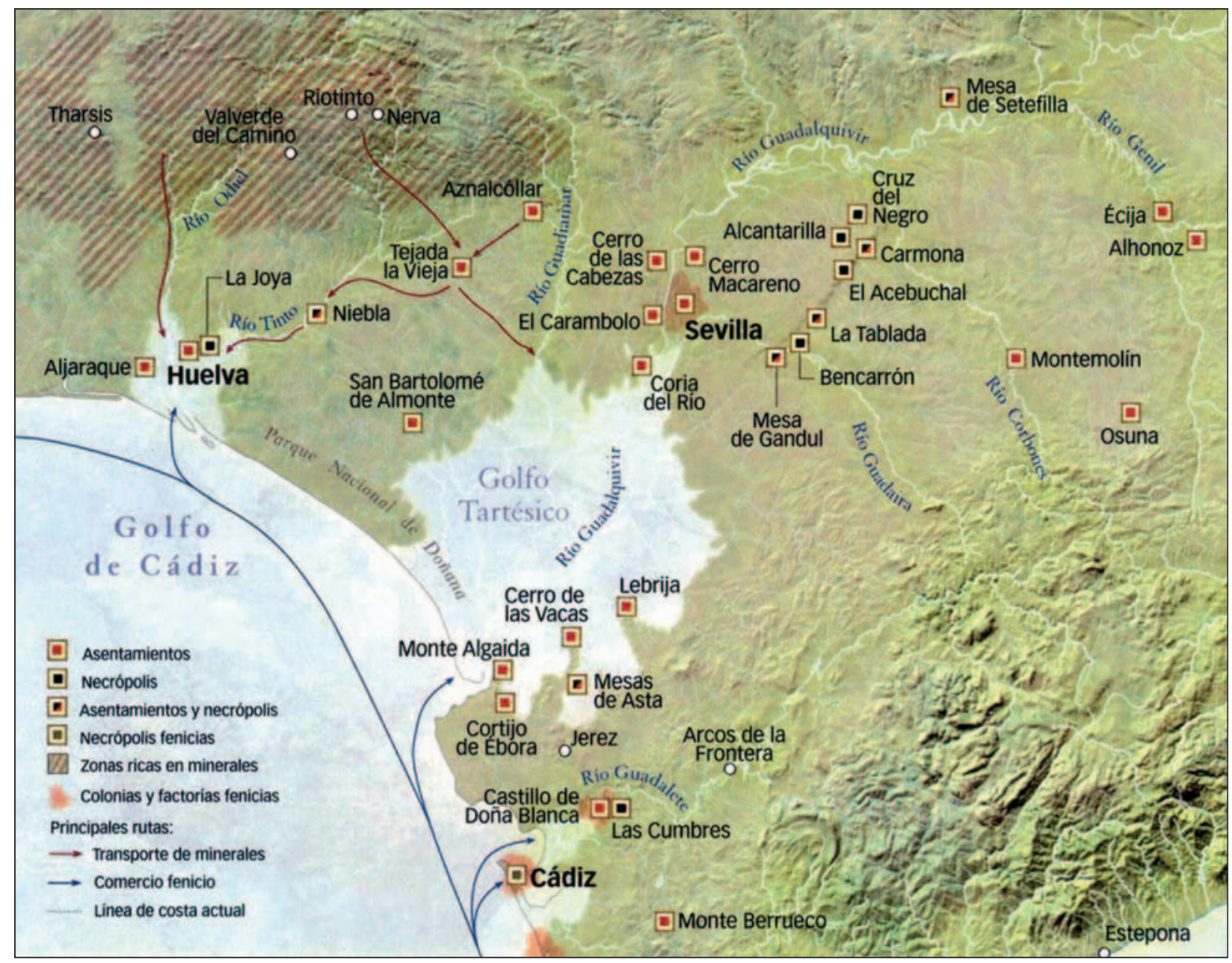

Figura 1. Alhonoz en la geografía tartesia de época orientalizante.(Cartografía F. Sánchez-Eosgis para RBA).

cerámicas fenicias y a mediados del VII a.C., en la plenitud de la etapa orientalizante en tierras del Guadalquivir, el núcleo poblacional alcanzó una extensión próxima a las 15 ha y se consolidó como centro hegemónico en la zona (López Palomo, 1999). Posiblemente entonces, o algo más tarde, se construyó un primer cinturón defensivo (Moret, 1996: 541-542).

En la actuación arqueológica de 1977 se hizo un sondeo junto al castillo medieval que se levanta en la zona más alta del lugar, dominando un amplio entorno (Fig. 2), y se documentó una secuencia de más de seis metros de potencia y diez estratos arqueológicos que se fecharon entre los siglos IX y principios del II a.C. (López Palomo, 1981a, 47-81; Idem, 1999: 83-97)2. La abundancia y excelente conservación de la colec-

2 Salvo que se indique lo contrario, los datos que reseñamos a continuación han sido tomados de esta publicación más reciente, en la que el autor sintetiza sus trabajos en el yaci- ción de cerámica exhumada en el estrato II y su importancia como fuente documental de la religiosidad turdetana, prácticamente desconocida, ha hecho que se multipliquen las referencias a estos hallazgos. No obstante, hay no poca confusión en los datos estratigráficos y cronológicos que manejan algunos investigadores, de ahí que nos parezca pertinente insistir en el análisis del contexto arqueológico de los depósitos de Alhonoz y de su significado religioso. El lenguaje simbólico con que se expresan los cultos en este oppidum traduce un ambiente de fuerte interacción cultural en el interior de la región que los romanos llamaron Turdetania, derivado sin duda de la presencia estable de poblaciones púnicas tanta veces reivindicadas por el profesor Manuel Bendala (1994, entre otros), al que con el mayor afecto dedicamos estas notas.

miento durante casi una década y asume hipótesis interpretativas diferentes de las iniciales sobre los resultados de la intervención de 1977. 


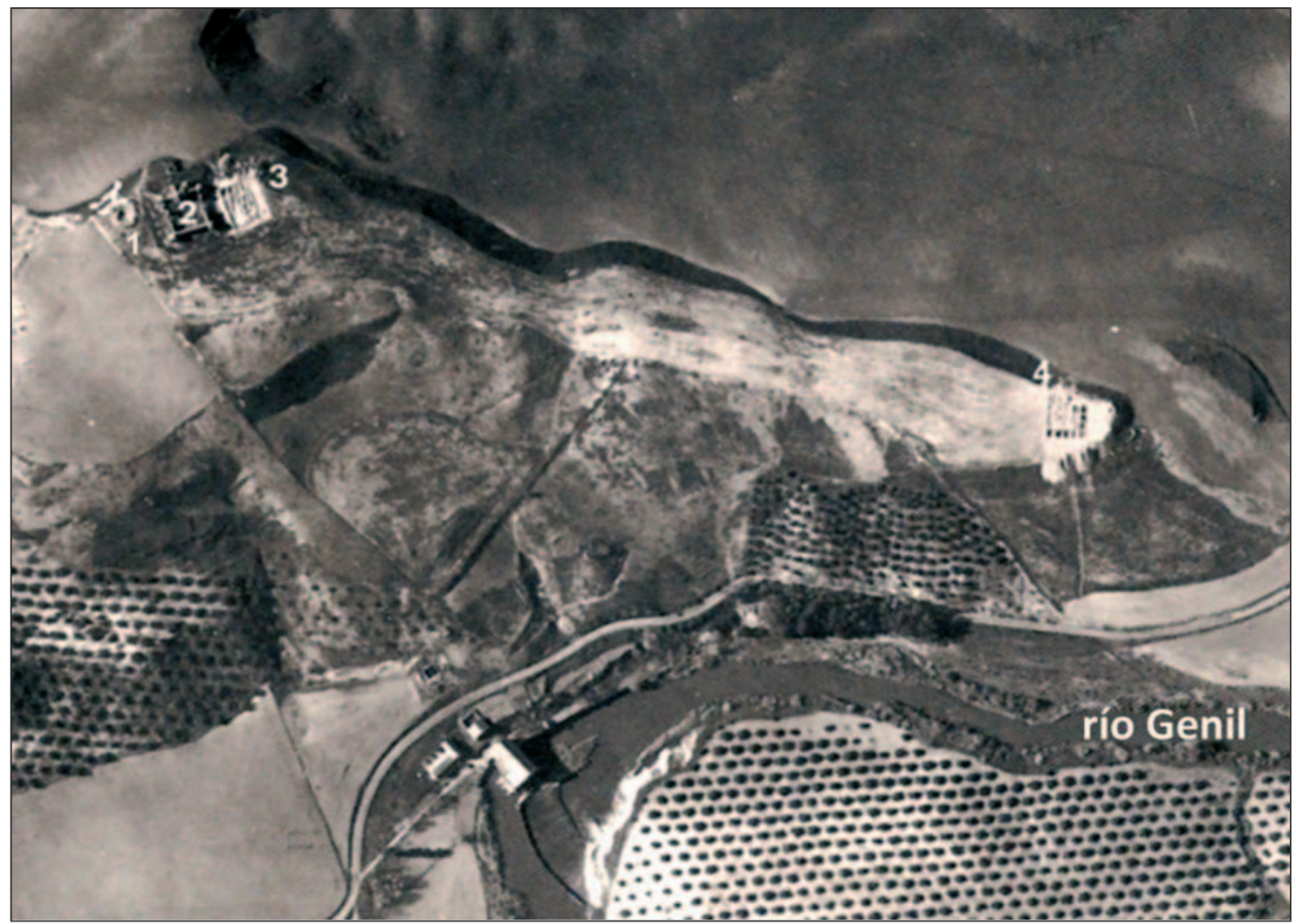

Figura 2. El oppidum de Alhonoz a orillas del Genil. Castillo medieval (2) y excavaciones de 1977 (1), 1978 (3) y 1979 (4). (López Palomo, 1980: 18).

\section{EL CONTEXTO DE LOS DEPÓSITOS}

Del estrato II de la citada estratigrafía de 1977 (Fig. 3) se recuperaron centenares de piezas de cerámica completas, la mayor parte de tamaño reducido, platos y cuencos de distintos tipos, cuencos-lucernas, vasos caliciformes, toneletes, ollas con o sin asas y ánforas pequeñas, que constituyen un magnífico repertorio de alfarería turdetana. El estrato subyacente (III) contenía asimismo abundante cerámica, sobre todo cuencos y platos, fragmentados o completos, así como tapaderas, restos de ánforas y cuencos-lucernas, además de una campanita de bronce. Platos completos se registraron también en el estrato IV. Estas tres capas fueron seccionadas por un pequeño pozo u hoyo excavado en el terreno, de forma circular, con $1 \mathrm{~m}$ de diámetro y algo más de profundidad, en cuyo interior y entre cenizas se hallaron algunas formas de cerámica semejantes a las del estrato II, dos objetos de piedra pulimentada, parte del soporte de un timiaterio chipriota de bronce, la mitad superior de una estatuilla del mismo metal que representa a una divinidad femenina con atributos guerreros y un denario romano de plata acuñado en el año 138 a.C.
El hecho de que las piezas estuvieran apiladas por formas y tamaños (Fig. 4) y de que no se apreciaran huellas de uso en ellas, hizo que se viera en el estrato II un conjunto excepcional de cacharrería preparada para su venta, sin que el carácter de miniatura de muchas de las piezas, el hallazgo en el interior de una olla de una lámina de plata con representación de ojos y símbolos astrales, o la presencia de objetos litúrgicos y de significado claramente religioso en el hoyo colmatado de cenizas, hicieran sopesar otras posibles interpretaciones. La publicación del depósito portugués de Garvâo puso en evidencia el carácter religioso del conjunto de Alhonoz (Beirâo et alii, 1985: 118) y hoy se acepta de forma unánime que los materiales en cuestión - metálicos y cerámicos - son exvotos y ofrendas de un santuario existente en el lugar y todavía por descubrir, aunque quedan muchas dudas por despejar sobre los contextos en que se hallaron. El pozo, por ejemplo, se interpretó primero como horno, por suponer que las estructuras y materiales hallados en la excavación tenían que ver con un centro de producción alfarera (López Palomo, 1981a: 45, 47, 55-56 y 90), y después como favissa (Almagro-Gorbea y Domínguez de la Concha, 1988-89: 365) y como 


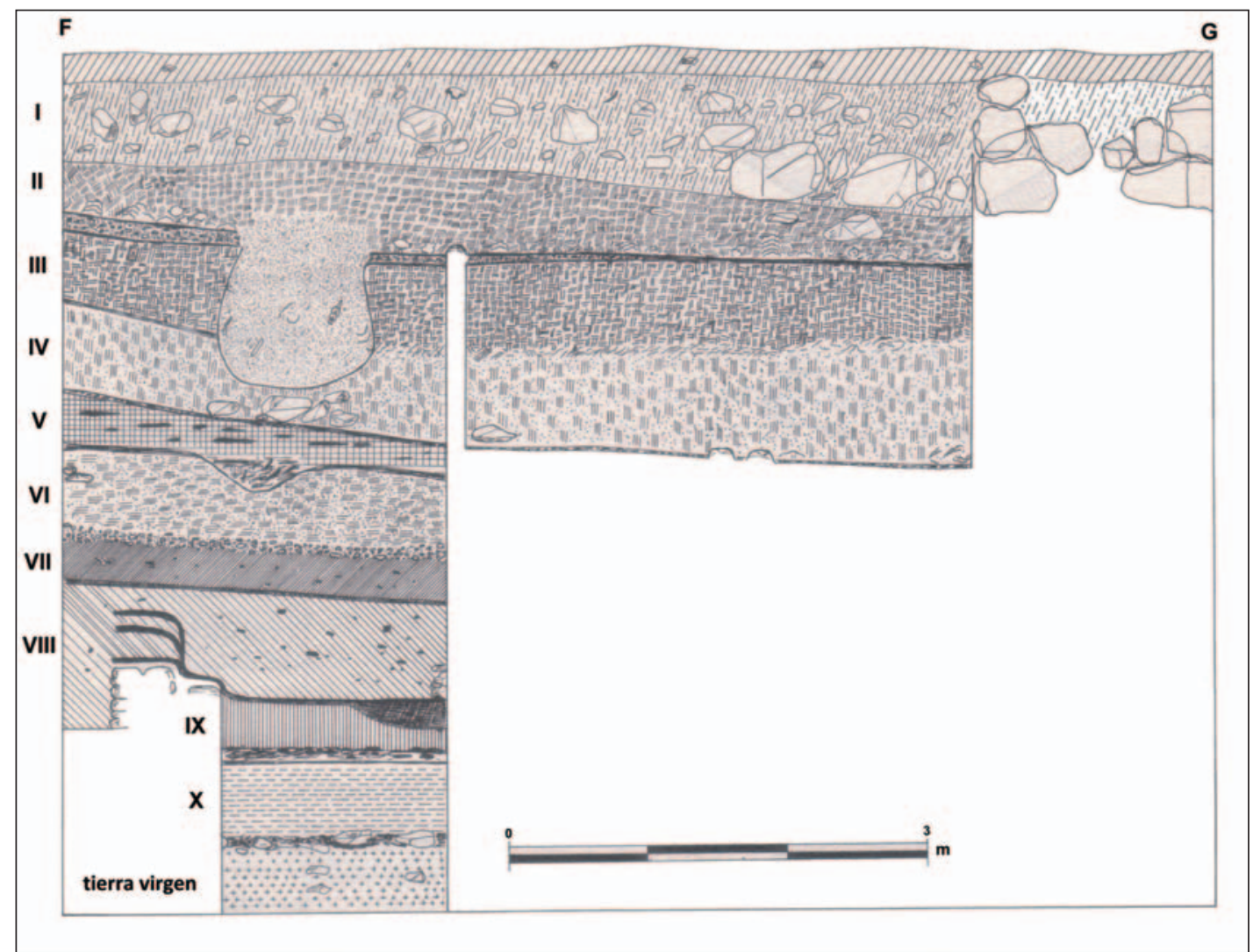

Figura 3. Alhonoz, 1977. Los depósitos en la secuencia estratigráfica (II-IV). (López Palomo, 1981a: Fig. 8).

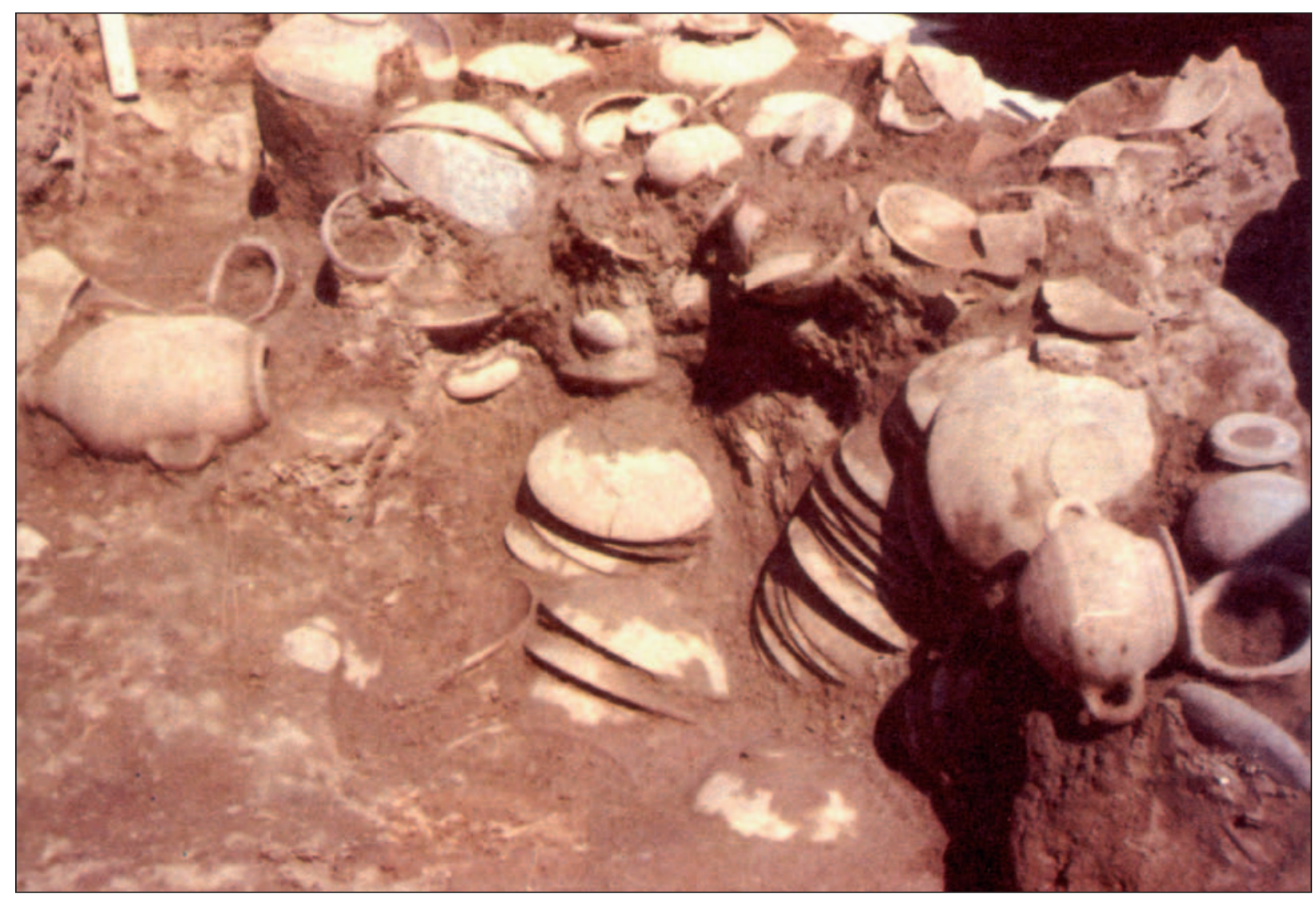

Figura 4. Alhonoz, 1977. Excavación del depósito de cerámica del estrato II. (López Palomo, 1999: Lám. XXII). 
ustrinum (López Palomo, 1999, 89). En cuanto al depósito de cerámica del estrato II, se ha considerado un puesto de venta (López Palomo, 1981a: 55) y el almacén de un santuario (Idem, 1999: 85) o de un palacio (Moneo, 2003: 54), apuntándose también que pudiera tratarse de un depósito votivo (Domínguez Monedero, 1995: 49; Moneo, 2003: 54). Aunque no está justificado, los estratos III y IV han sido ignorados en estas valoraciones.

En una revisión posterior, el propio excavador relacionó el estrato II y la que llamó "fractura" (hoyo) con un muro perteneciente a un edificio de uso cultual cuyo origen remontaría a época orientalizante (López Palomo, 1999: 89 y 128). Este supuesto nos parece improbable y poco fundamentado, a juzgar por los datos disponibles. El soporte de timiaterio de tipo "chipriota" de los siglos VII-VI a.C. (Jiménez Ávila, 2002: 173-174 y 399), pudo ser parte de un equipo litúrgico, pero del supuesto santuario de época orientalizante sólo se habría documentado un grueso muro que arrancaba del estrato VI (López Palomo, 1999: 89, lám. XIX), lo cual no implica que el hoyo y los restos constructivos tengan la misma datación. Por otra parte, sería el único caso en la protohistoria meridional de continuidad de un mismo edificio sacro durante varios siglos. La relación que se establece con el edificio de Cancho Roano (Ibidem: 128) está condicionada por el paralelismo funcional que se ha visto entre el complejo extremeño y un hipotético palacio orientalizante de Alhonoz al que pertenecerían el timiaterio y la diosa armada hallados en el pozo, que son interpretados como sacra de un santuario dinástico depositados en una pequeña favissa. El edificio “ibérico" próximo al sondeo de 1977, prolongaría la arquitectura de prestigio de tradición orientalizante hasta tiempos romanos (Almagro-Gorbea y Domínguez de la Concha, 1988-89: 365-366; Almagro-Gorbea y Moneo, 2000: 22-24). Pero esta hipótesis tiene de momento un anclaje arqueológico poco sólido. La cronología de los objetos depositados en el hoyo es muy dispar y sólo el soporte de timiaterio es propiamente orientalizante. Finalmente, debemos recordar que no se encontraron estructuras de la misma época orientalizante ni bajo el edificio tardío ni en el sondeo practicado al suroeste del mismo (López Palomo, 1999: 100).

La secuencia del yacimiento y la valoración cronológica del sondeo de 1977 fueron cuestionadas hace años (Escacena, 1987a: 275, 279), pero cabe hacer otras observaciones al respecto. López Palomo (1999: 131-134) incluye los estratos II a IV y el pozo/hoyo que los perfora en la fase IV (ibérica) de la secuencia de Alhonoz, cuyo inicio sitúa a fines del V a.C., aunque su desarrollo se produciría a partir de mediados del siglo siguiente para acabar a principios del II a.C. Insiste el citado autor en que el estrato II debe datarse en la primera mitad del siglo III a.C. (Ibidem: 466; cf. Idem, 2002: 110-111) y no a fines de esta centuria y principios de la siguiente como sostienen otros investigadores (Escacena, 1987a: 279). En las tres capas citadas se hallaron piezas cerámicas completas, más numerosas y con mayor variedad tipológica en la superior (II), pero no queda claro qué relación estratigráfica hay entre ellas. En una primera publicación (López Palomo, 1979: 72), los estratos II-IV se consideraron en su conjunto como "centro de distribución de cerámica", pero en trabajos posteriores se señalan diferencias funcionales entre ellos. El estrato II se interpreta como "almacén de lugar de culto", en tanto que el III se considera un "vertedero" para desechos de actividades rituales (Idem, 1999: 85 y 88). Este último tenía "la misma naturaleza geológica" y un repertorio de formas idéntico al del estrato II, pero se señala la existencia de un pavimento entre ambos que, obviamente, sellaría la capa subyacente (López Palomo, 1999: 83, fig. 82). Por otra parte, entre este suelo y la base del estrato III, en la que se halló "un amasijo de platos rotos" y algunas piezas completas, mediaba un grueso paquete de tierra carente de material arqueológico, cuya formación se achaca a "factores naturales" (Idem: 88). Por último, el estrato IV se iniciaba bajo el nivel de tiestos rotos del estrato III y en su base todavía se hallaron platos, fragmentados y completos. De la información que se nos ofrece, sacamos la impresión de que está justificada la diferenciación de los estratos II y III, pero no tanto la que se establece entre este último y el IV. Posiblemente, entraron aquí en contacto unidades de estratificación de diferente cronología. Los restos de "destrucción antigua" que se identificaron en una zona de este estrato, podrían explicar la presencia en él de algún fragmento de cerámica a mano de fechas más altas (López Palomo, 1999: 88, fig. $102, n^{\circ} 4$ ), aunque no excluimos la posibilidad de que se trate de elementos residuales depositados fuera de su contexto original. De ser así, tendríamos al menos dos depósitos de materiales amortizados en momentos sucesivos no necesariamente distanciados en el tiempo - en 
el mismo sitio, quizá una amplia fosa excavada en el terreno. En cuanto al hoyo o "fractura", se dice que se iniciaba en el estrato I y que permaneció abierto durante mucho tiempo, lo que explicaría la dispar datación de los objetos que contenía (López Palomo, 1981a: 83; 1999: 89 y 382). Sin embargo, el relleno de cenizas de este pequeño pozo parece homogéneo (Idem, 1999: 89, fig. 82) y producto de una deposición intencional y rápida. Es posible que estuviera delimitado por un "dudoso murete circular, muy desmontado, asentado directamente sobre el pavimento" que delimita los estratos II-III (Ibidem: 83, fig. 84). Por otra parte, en la primera descripción del estrato II y en la ilustración gráfica del perfil estratigráfico se indica que se excavó a partir del pavimento de la base de dicho estrato II (López Palomo, 1981a: 51,55 , fig. 8), lo que significaría que es anterior a éste último, que lo cubre por completo (Fig. 3), y, en consecuencia, tendríamos que fechar el estrato II con posterioridad al 138 a.C., que es la fecha de la moneda que se encontró dentro del hoyo, un denario romano de plata acuñado por el magistrado monetal C(aius)RENI(us), con cabeza de Dea Roma en el anverso y Juno en biga de cabras en el reverso.

Al margen de los problemas de interpretación que plantea la estratigrafía de este sondeo de 1977, que no acertamos a resolver con la información que poseemos, pensamos que hay otros datos a favor de una cronología republicana para el estrato II, posterior a la defendida por el estudioso del yacimiento. Como bien se ha señalado (López Palomo, 1999: 132; Ferrer y García Fernández, 2008: 204, 206), la tipología y la decoración de la cerámica turdetana ayuda poco a precisar la datación de estos contextos, dado que ni una ni otra cambian de forma significativa durante siglos ${ }^{3}$. Sin embargo hay en el depósito formas que no están tipificadas en los repertorios del Bajo Guadalquivir (Ferrer y García Fernández, 2008), como los pequeños cuencos de cerámica común clasificados como tapaderas (López Palomo, 1981a: 62, fig. 17; 1999: 502, fig. 324), para los que sí encontramos paralelos en la

3 El mismo problema se acusa en la zona colindante con las tierras altas de Turdetania en las que se ubica Alhonoz (Vaquerizo, 1999: 140-149).

4 Niveau de Villedary (2003: 184) sugiere parentesco con las formas 34 y 35a de Lamboglia; cf. Beltrán, 1990: fig. 10, 33.

5 Entendemos que la inclusión del estrato II del corte de 1979 en la misma fase IV (ibérica) que el II de 1977 debe ser un cerámica "Tipo Kuass", con la diferencia de que en esta producción gaditana las superficies se recubren de engobe. Concretamente, los cuencos de reborde triangular o con doble reborde (interior y exterior) están muy cerca del tipo XI-B ("salero") de la clasificación de Niveau de Villedary (2003: 81, fig. 21, 3), representativa de la fase más tardía de dicha producción. La forma no tiene tradición en la alfarería púnica occidental y se cree inspirada en tipos campanienses desconocidos en la región antes del siglo II a.C. (Eadem: 183-184 y 280 fig. 63; Ventura, 2001: 327-328). Finalmente, una datación en la segunda centuria a.C. para el estrato II se deduce asimismo de la propia secuencia que reconstruye el excavador. El controvertido estrato representa el final de la fase IV (ibérica) en el sondeo de 1977, ya que está cubierto por el estrato I, que pertenece a la fase $\mathrm{V}$ y última de dicha secuencia. Pues bien, para el inicio de esta última se proponen fechas del segundo cuarto del II a.C. (López Palomo, 1999: 134), que no pueden estar muy alejadas de las del final de la etapa anterior, puesto que no hay discontinuidad en la estratigrafía entre los estratos incluidos en una y otra fase.

Por las razones señaladas, parece, pues, consecuente datar la amortización del depósito del estrato II en un momento avanzado del siglo II a.C. ${ }^{5}$. La relación estratigráfica entre esta capa y el hoyo no está del todo clara, como hemos visto, pero es seguro que la datación de este último es posterior al 138 a.C., fecha confirmada por el denario de C(aius) RENI(us) depositado en su interior. López Palomo (1999: 89) opina que la estructura estuvo en uso durante siglos, pero los datos que tenemos nos hacen pensar en una deposición rápida y, probablemente, única. En el hoyo se hallaron, además de los objetos metálicos ya citados, formas cerámicas semejantes a las del estrato II, incluidas las llamadas tapaderas (López Palomo, 1999: 89). El mismo hecho se repite en el estrato III y, en parte, en el IV (Ibidem: 88), que deben interpretarse asimismo como capas de amortización de materiales de uso ritual y votivo en una misma favissa ${ }^{6}$ que se clausura con el

error, ya que aquél se adscribe igualmente a la fase posterior (V) (López Palomo, 1999: 106 y 132- 134). De no ser así, habría que considerar el hallazgo en él de productos campanienses A y B (formas Lamboglia 36 y 1, respectivamente) (Idem: fig. 324) no anteriores al último cuarto del siglo II a.C. (Vivar, 2005: 34; Principal, 2005: 54).

6 En el significado de favissa seguimos a Garbati, 2012. 
estrato II. Con los datos disponibles, no podemos saber si ésta era una simple fosa excavada en la parte alta de la ladera del cerro, si guardaba relación con alguna de las estructuras constructivas detectadas, o si estaba dentro o fuera del edificio de culto al que pertenecía. Algunos ejemplos comparables por su contenido y proximidad en el tiempo ofrecen cierta diversidad a este respecto. La favissa de Garvâo, datada a fines del III a.C., era una fosa oval excavada en una ladera y delimitada parcialmente por un muro de escasa entidad (Beirâo et alii, 1985: 60 y 140-141). El profundo pozo votivo de El Amarejo se excavó en una zona exterior de tránsito entre edificios que, probablemente, formaban parte de un mismo complejo sacro ${ }^{7}$. Por el contrario, la favissa subterránea del santuario urbano de San Miquel de Líria fue construida en una esquina del patio que precedía a la cella (Aranegui, 1997) ${ }^{8}$. La referencia a un pavimento en la base del estrato II de Alhonoz podría hacer pensar en un espacio edificado, pero no parece que fuera así. De hecho, como se recordará, el sitio se interpretó en principio como "lugar de comercialización a cielo abierto" (López Palomo, 1981a: 55).

Tampoco podemos precisar si medió algún tiempo entre la formación de los distintos estratos del relleno o si, por el contrario, las tres capas corresponden a un único acto de amortización, como en los casos de Garvâo (Beirâo et alii, 1985: 134) y de El Amarejo (Blánquez, 1996: 158). Esta última posibilidad no excluiría que el depósito pudiera reunir objetos de diferente cronología, teniendo en cuenta que los materiales que lo componen debieron permanecer algún tiempo conservados en el santuario antes de su amortización ritual en la favissa ${ }^{9}$, pero la abundante vajilla local que contenía no es de ninguna ayuda en este sentido. Como decíamos más arriba, los repertorios turdetanos se repiten durante siglos y se mantienen sin grandes cambios hasta tiempos romanos. El horizonte ibérico tardío del poblado del Cerro de la Cruz de Almedinilla, nos brinda un buen ejemplo del arraigo de la cerámica ibérica tradicional en la subbética cordobesa cercana a

7 Broncano (1989: 232 y 239) opina que se trata de un pozo en el que se depositaron ofrendas y se realizaron rituales con carácter periódico hasta el final del poblado (fines del III o principios del II a.C.), pero el hecho de que casen fragmentos cerámicos recogidos a diferentes profundidades, aboga a favor de la interpretación de la estructura como favissa (Blánquez, 1996: 158).
Alhonoz en el último tercio del siglo II a. C. (Vaquerizo, 1999: 140-149, láms. 40 y 42-48). Por otra parte, no hay que perder de vista el carácter conservador de la religión. En la necrópolis del Olivar Alto (Utrera, Sevilla), vasitos de paredes finas, ungüentarios de vidrio y otros materiales de los siglos I-II de J. C. se asocian a urnas pintadas de larga tradición local (Puya y Campos, 1983).

En cuanto al hoyo, las cenizas que lo colmataban y las piezas que contenía permiten caracterizarlo como un pequeño pozo ritual, quizás un bothros, en el que se depositaron restos de hogueras relacionadas con prácticas de culto, ofrendas, exvotos y objetos litúrgicos. Aunque no se mencionan restos orgánicos (huesos, semillas u otros) que podamos relacionar con sacrificios de animales y ofrendas de alimentos, se señala la presencia de dos piezas de piedra pulimentada que podrían haberse usado como mazas sacrificiales (López Palomo, 1999: lám. XXX).

El hecho de que el timiaterio esté incompleto y roto el pequeño bronce de la diosa guerrera, puede significar que estaban ya en desuso cuando se amortizaron, o bien que aquél se despiezó y la imagen se fragmentó para impedir que pudieran profanarse en reutilizaciones posteriores. La fecha post quem que proporciona la moneda romana impide datar el conjunto antes del último tercio del siglo II a.C. La presencia en él de una pieza de Campaniense B de tipo Lamboglia 4 (López Palomo, 1999: fig. 324, en posición invertida), aconseja una datación algo más baja incluso, ya que el marco cronológico de dicha forma va desde el último cuarto del siglo II a fines del tercer cuarto del I a.C. (Principal, 2005: 53). El hallazgo conjunto de materiales de diferente datación no es necesariamente indicativo de una larga etapa de uso y es frecuente en contextos sacros. Hallazgos como la conocida dama de Galera (Olmos, 2000-2001: 358), o el timiaterio de Cástulo (De la Bandera y Ferrer, 1995), prueban que la conservación de objetos religiosos durante siglos no es un hecho excepcional.

8 El final del santuario se data hacia 175-150 a. C. (Aranegui, 1997: 104).

9 Los citados depósitos de Garvâo (Beirâo et alii, 1985: 111) y de El Amarejo (Blánquez, 1996: 159), entre otros, también contenían materiales de distintas fechas. 
Como hemos comentado, no queda del todo claro si el hoyo es o no anterior a la clausura definitiva de la favissa, pero, en cualquier caso, ésta se llevó a cabo en el mismo siglo II a C. y, probablemente, en fechas próximas. Los asentamientos del Valle Medio del Genil, como sus vecinos de las campiñas del Guadajoz, vivían en ambiente de guerra desde fines del III a.C. La arqueología documenta graves signos de violencia en la región durante las últimas décadas del siglo II a. C. (Vaquerizo, 1999: 55), por lo que no es impensable que el clima de inseguridad o la inminencia de algún episodio bélico forzara la ocultación ritual de los objetos sagrados del santuario. Años después, la guerra y sus consecuencias llevarían al abandono definitivo del asentamiento. Su final se sitúa hacia mediados del siglo I a.C. y se relaciona con la contienda entre pompeyanos y cesarianos (López Palomo, 1999:134), cuyo final se libró en un escenario tan próximo, que algún autor ha considerado el oppidum de Alhonoz como posible solar de la ciudad de Munda ${ }^{10}$.

\section{El CULTO EN PERSPECTIVA ARQUEOLÓGICA}

Los objetos depositados en la fosa y en el pozo son nuestra única fuente de información sobre las prácticas de culto que se desarrollaban en un santuario urbano situado, probablemente, en el entorno próximo. La primera contenía casi exclusivamente cerámica, más de 600 piezas sólo en el estrato II, la mayoría completas y sin señales aparentes de uso (Fig. 5) ${ }^{11}$. En el conjunto predominan los cuencos semiesféricos, de entre 10 y 18 $\mathrm{cm}$ de diámetro máximo, que se hallaron por centenares apilados en posición invertida. En general, carecen de la banda roja pintada sobre el borde que presentan los ejemplares similares recuperados en las dos capas inferiores del depósito. Muy abundantes son también los cuencos-lucerna de borde entrante ${ }^{12}$ y otros más pequeños ${ }^{13}$, con reborde exterior, que se describen como tapaderas por tener constancia en el registro de que a veces se usaron como tales, unos y otros sin decorar. Platos de borde exvasado con bandas pintadas y escudillas, algunas de tamaño reducido, con y sin

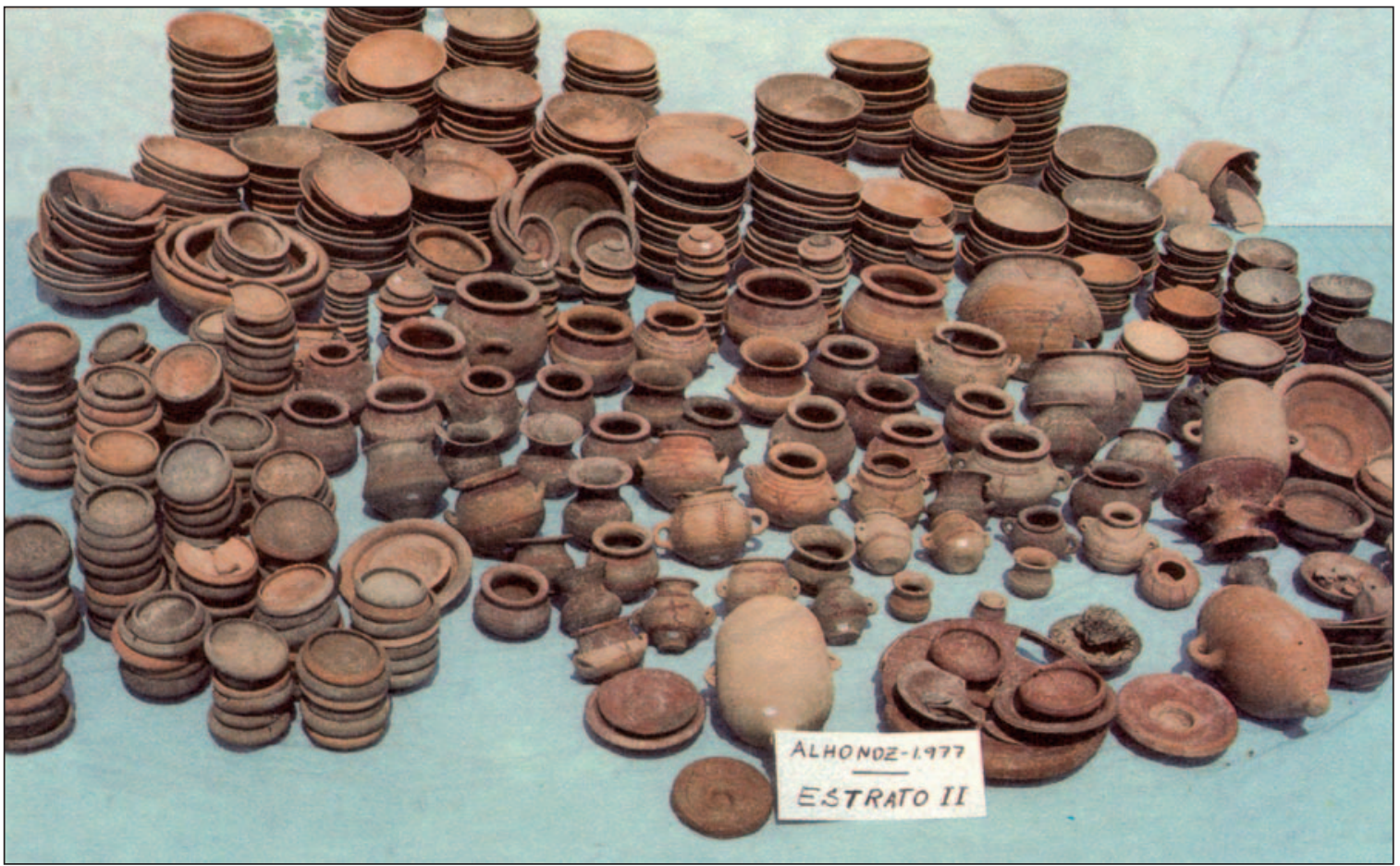

Figura 5. Alhonoz, 1977. Conjunto de cerámica del estrato II. (López Palomo, 1999: Lám. XXIV).

${ }^{10} \mathrm{Vid}$. resumen sobre el tema, con bibliografía, en Rodríguez Neila, 1988: 273.

${ }^{11}$ Para mayor información, cf. López Palomo, 1999: 429503. Con alguna excepción, las formas documentadas en Alhonoz son corrientes en la alfarería prerromana del Valle del Guadalquivir, estudiada por Escacena (1987b) y Pereira (1988).

12 Con diámetro de boca (interior) comprendido entre 7 y 11 $\mathrm{cm}$.

${ }^{13}$ Ninguno alcanza los $7 \mathrm{~cm}$ de diámetro interior en la boca. 
decoración, estas últimas provistas de asas horizontales insertas en la zona más ancha del vaso, completan el repertorio de formas abiertas más corrientes. Pieza única es una copa de pie alto y cuerpo en forma de casquete esférico ${ }^{14}$, pintada de rojo a excepción del fondo interior, y con una acanaladura en el borde para encajar una tapadera. $\mathrm{La}$ forma carece de paralelos en cerámica turdetana, pero su mayor originalidad está en las tres figuras de paloma aplicadas sobre la pared exterior, en la zona de unión entre el cuerpo del recipiente y el pie. El hallazgo de aves sueltas de la misma especie hace pensar que había otras piezas similares (López Palomo, 1981a: 72).

Entre las formas cerradas, menos numerosas, las más frecuentes son las ollas de cuerpo esférico u ovoide, sin cuello y con borde vuelto al exterior. Su altura oscila entre 6 y $12 \mathrm{~cm}$ y tienen dos asas insertas - vertical u horizontalmente- sobre la parte más ancha de la pared. Están decoradas con motivos pintados de rojo oscuro, esteliformes (de 4,6 y 8 puntas) y representaciones de palmas, ramas o espigas, que son exclusivos de esta forma, hasta el punto de que ni siquiera se repiten en las piezas de morfología similar desprovistas de asas, igualmente bien representadas en el conjunto (Fig. 6 y 7). Siguen en importancia numérica un lote de vasos diminutos (de 3 a $6 \mathrm{~cm}$ de altura) de boca ancha acampanada, con o sin asas, cuya morfología responde, en unos casos, a los que llamamos caliciformes, y en otros guardan cierto parecido con los vasos "à chardon" de tiempos anteriores. Todos presentan decoración de bandas y franjas rojas, o bien rojas y negras. Completan el repertorio dos ánforas de tamaño reducido ${ }^{15}$, tres toneletes que presentan un orificio en el fondo por el que se podría verter el líquido contenido en el interior ${ }^{16}$, el cuello de un frasco de boca muy estrecha, con asas que arrancan del borde, y un recipiente de cuerpo globular, con base aplanada, decorado con trazos de pintura roja dispuestos de forma radial en torno a su estrecha boca. Es parte de un kernos y conserva la pared que lo unía a otro de los elementos que componían la pieza. Como se recordará, también el pozo contenía platos, cuencos-lucerna y "tapaderas" semejantes a los del estrato II.
Hay en el conjunto piezas que pudieron tener un uso doméstico como vajilla de mesa o de cocina, pero en buena parte parecen producciones expresamente destinadas a usos cultuales, bien en actos de devoción privada o en ceremonias festivas de carácter colectivo. En su mayor parte son de pequeño tamaño, a veces auténticas miniaturas, un hecho conocido en todo el Mediterráneo (Segarra, 2006) que ha sido documentado también en santuarios peninsulares de fechas próximas a las que defendemos para los depósitos de Alhonoz, como el de Edeta-Liria (Aranegui, 1997: 107), o los más cercanos de Torreparedones (Córdoba) y Las Atalayuelas de Fuerte del Rey (Jaén), en los que encontramos otras coincidencias, como el uso de un repertorio cerámico estandarizado (Rueda, 2011: 233-234). Los cuencos y las ollas, las formas más frecuentes en Alhonoz, son también "la vajilla ritual básica" en Las Atalayuelas (Eadem, 2011: 234, Fig. 121), pero hay diferencias morfológicas y decorativas entre los repertorios de uno y otro yacimiento. Las pequeñas ollas con dos asas sobre el cuerpo, en posición vertical $\mathrm{u}$ horizontal, son tan poco corrientes fuera de Alhonoz como las decoraciones fitomorfas y astrales que tienen muchas de ellas. En el santuario periurbano de Torreparedones, como en Alhonoz, abundan los vasos caliciformes y los cuencos-lucernas de borde entrante (Fernández Castro y Cunliffe, 2002: 60, lám. 41; Morena, 2011: 253 y 254). El carácter ritual y votivo de los primeros como vasos de libación, está muy contrastado en la religiosidad prerromana (Izquierdo, 2003), y es igualmente frecuente el hallazgo de lucernas en contextos sacros. Naturalmente estas pudieron tener una función práctica de iluminación, dentro del santuario o en celebraciones nocturnas (Marín, 2010: 220-221), pero el elevado número de ejemplares hallados en el depósito, hace pensar más bien en ofrendas de luz tan arraigadas en la religiosidad popular hasta hoy.

El carácter sacro de los conjuntos cerámicos de Alhonoz es claro, pero no su significado preciso en las prácticas de culto que materializan. $\mathrm{La}$ utilización recurrente de las mismas formas y tamaños hace pensar en rituales con participación

\footnotetext{
${ }^{14}$ De unos $10 \mathrm{~cm}$ de altura y algo más de 15 de diámetro de ${ }^{16}$ Con $11 \mathrm{~cm}$ de ancho y 6,80 de alto, el de mayor tamaño. boca.

1518,20 y $19,70 \mathrm{~cm}$ de altura, aproximadamente.
} 

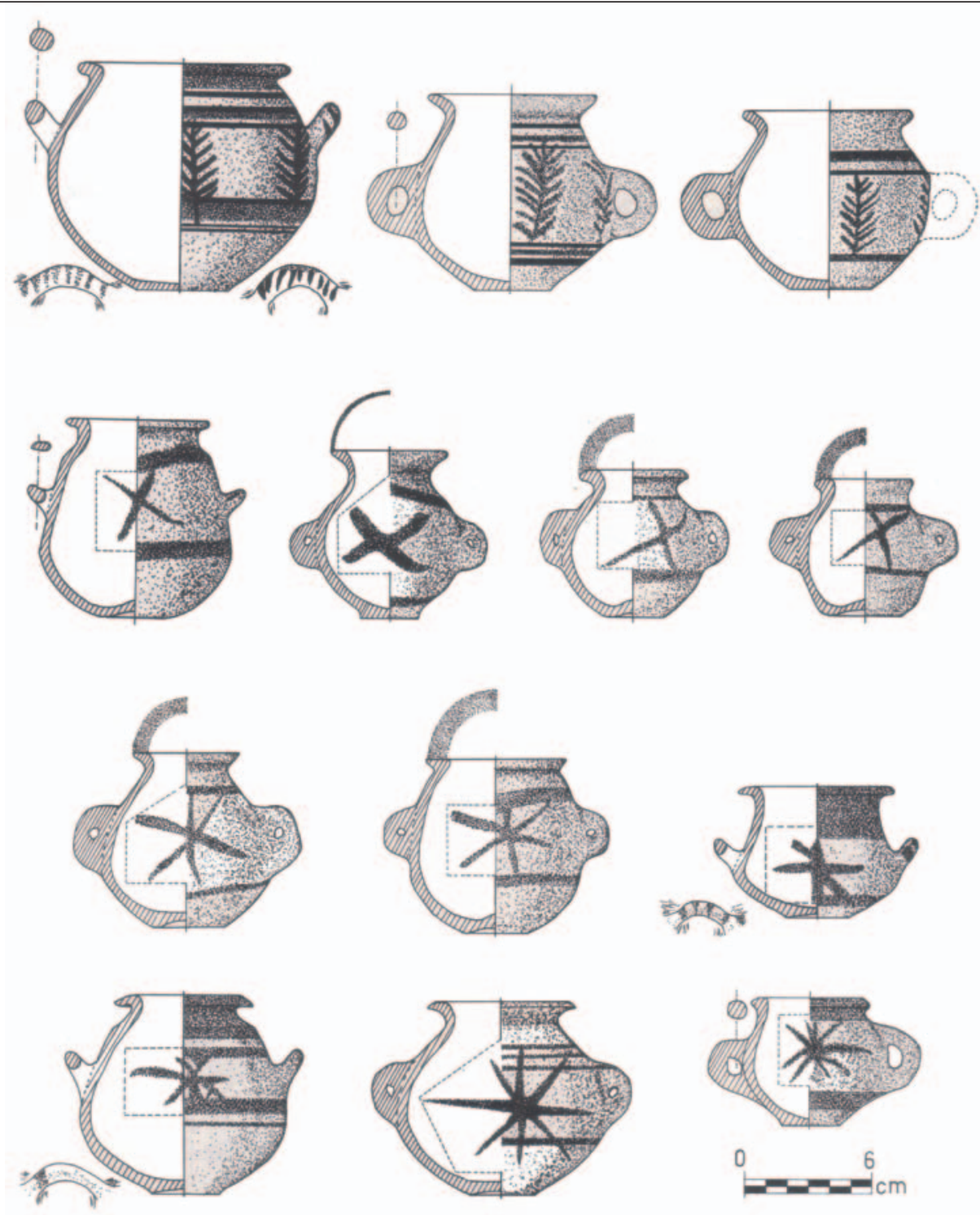

Figura 6. Alhonoz, 1977. Vasos del estrato II con representaciones simbólicas de carácter vegetal y astral. (Elaboración propia a partir de López Palomo, 1981a: Figs. 14-16).

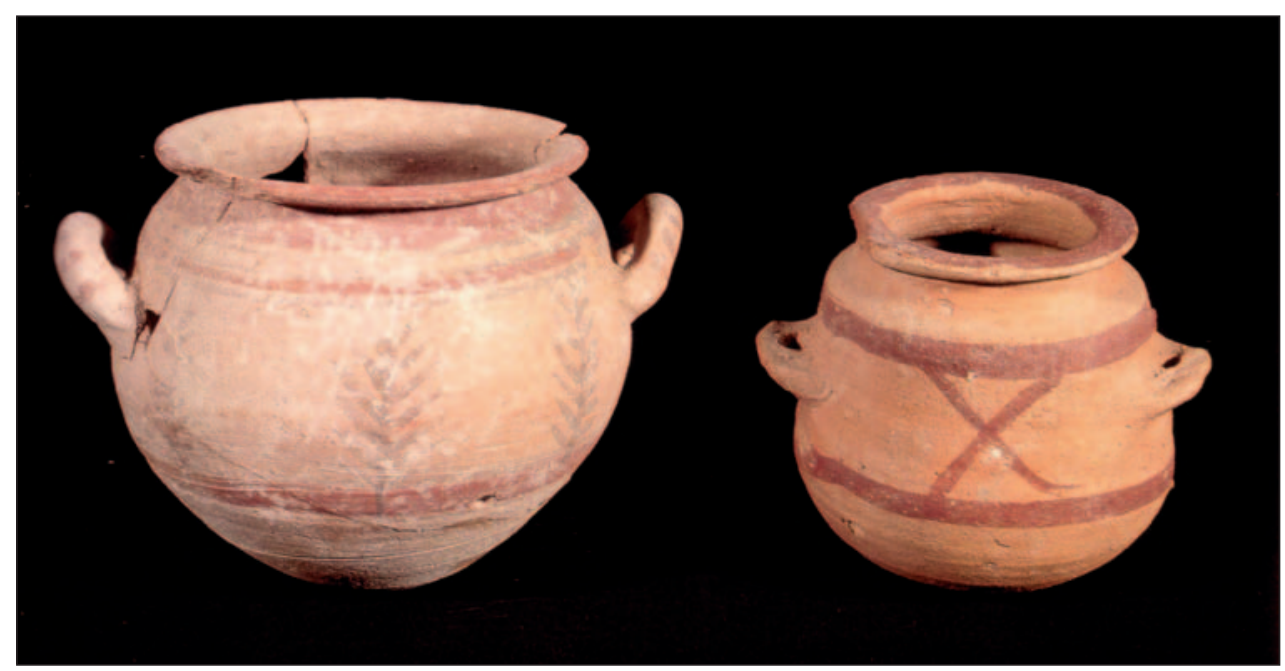

Figura 7. Alhonoz, 1977. Palmas y símbolo astral sobre vasos del estrato II. (Escacena 1992: 119). 
colectiva. Probablemente la mayor parte de la cerámica utilizada se producía en el asentamiento, quizá incluso en el entorno del santuario, y estaba destinada a actos de carácter público y comunitario, sin descartar las prácticas votivas de carácter personal. La abundancia de vasos con asas sobre la parte más ancha del cuerpo parece indicativa de gestos ritualizados en la forma de actuar ante la divinidad. La sujeción con ambas manos de un vaso está bien ilustrada por representaciones escultóricas ibéricas e ibero-romanas, aunque en ellas los oferentes sostienen recipientes caliciformes sin asas, asimismo abundantes, como se ha visto, en el registro de Alhonoz. El estudio detallado de I. Izquierdo (2003: principalmente 119$128,132)$ sobre estos documentos, entre ellos un conocido relieve procedente de Torreparedones (Morena, 1989), revela un interesante componente de género en estos rituales, en cuanto que los personajes que portan este tipo de vasos son mujeres, o a veces parejas, en tanto que los varones se representan llevando cuencos o páteras (Izquierdo (2003: 119- 123, 128 y 132).

Pese a las limitaciones que ofrecen los depósitos de Alhonoz para la reconstrucción del ritual, encontramos en ellos datos muy expresivos de la divinidad que se veneraba en el santuario, de algunos rasgos de su personalidad y de los poderes que se le reconocían. La pequeña estatuilla de bronce recuperada en el pozo la representa con atributos guerreros, como garante de la seguridad y supervivencia de la comunidad. López Palomo (1999: 396 y 400) incluye la pieza en la Fase III de la secuencia crono-cultural del yacimiento, una etapa cuyo final sitúa hacia el 500 a.C., quizá por apreciar en ella rasgos cercanos a modelos arcaicos griegos (Idem, 1981b: 250), pero el casco de cimera sagital que cubre su cabeza y la forma en que está trabajada su túnica, a base de incisiones verticales que simulan frunces, llevan a datarla en fechas más bajas, sin excluir que pudiera ser de época romana (Blech, 1982; Jiménez Ávila, 2002: 272). La iconografía de la deidad galeada tuvo gran aceptación en los primeros siglos del dominio romano en la región, a juzgar por las emisiones monetales. En tiempos tan convulsos, ningún otro emblema podía resultar más efectivo que la efigie de la patrona de la comunidad con atributos militares, garante de su seguridad y bienestar. Una interpretación en clave púnica relaciona esta iconografía con la faceta guerrera de la diosa Tinnit (García y Bellido, 1990: 375), pero no faltan quienes ven en las cabezas galeadas, no siempre femeninas, una mera moda que pudo introducirse en la Hispania Ulterior por cauces diferentes (Chaves y Marín, 2004), entre los que habría que considerar la imagen de la Dea Roma que se hace ahora familiar a través de emisiones como el denario de C(aius) RENI(us) hallado en el pozo votivo de Alhonoz.

Otros rasgos de la diosa poliada se expresan a través de una rica simbología. En el interior de una de las ollas sin asas del estrato II, que destaca de las de su clase por su mayor altura y por su decoración, se encontró una lámina de plata de 12 $\mathrm{cm}$ de longitud (Fig. 8). Tiene forma de antifaz

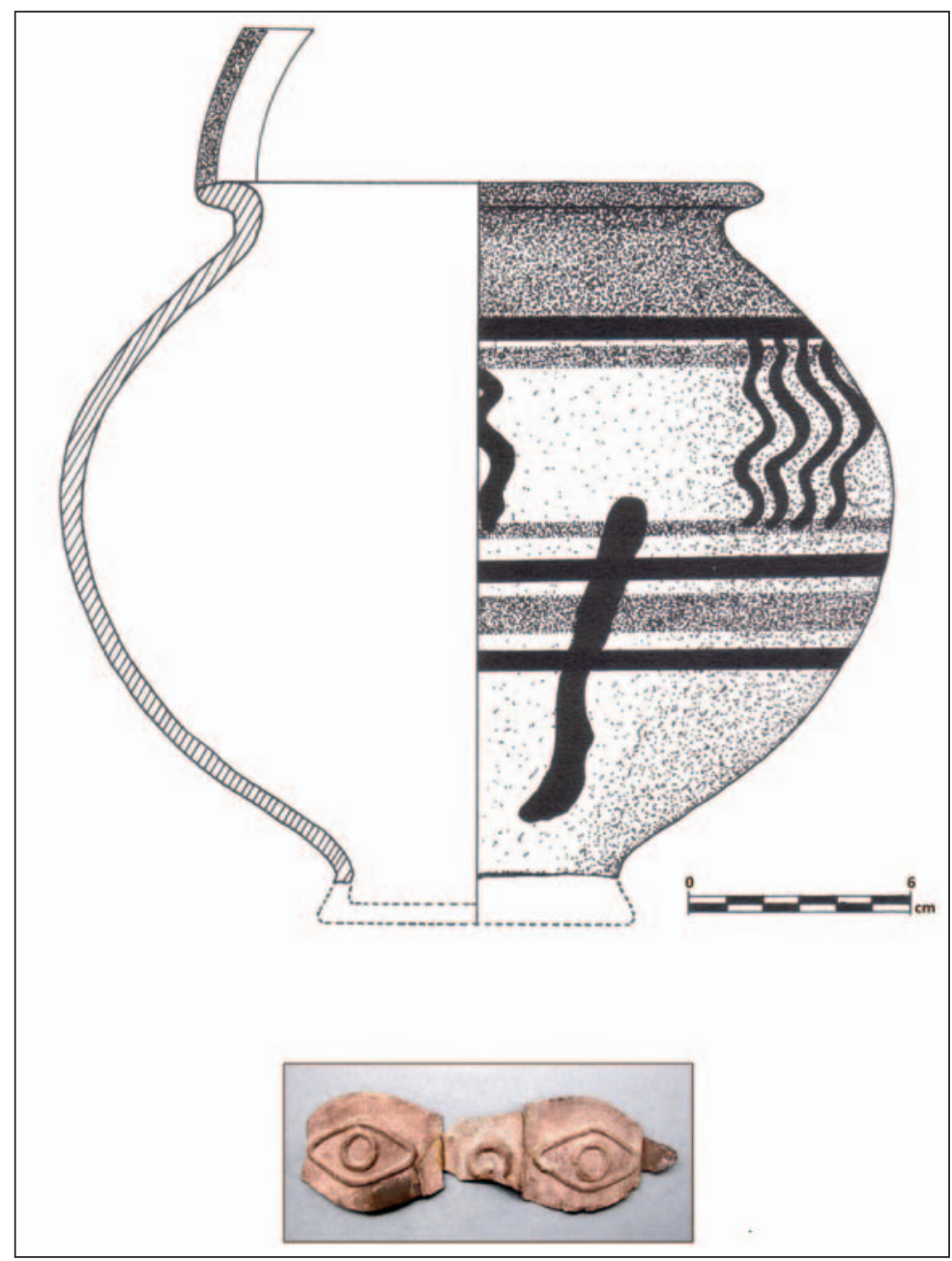

Figura 8. Alhonoz, 1977. Vaso del estrato II y placa de plata con representación de ojos hallada en su interior.

(1: López Palomo, 1981a: Fig. 10; 2: http://www.juntadeandalucia.es/cultura/WEBDomus/MASFREP1982_97_P) 
con sendos orificios en los extremos y dos ojos repujados entre los cuales, con idéntica técnica, se ha representado un creciente lunar con las puntas hacia abajo y un diminuto globo bajo el mismo. La pieza estaba fracturada y presentaba tres dobleces regulares, en sentido vertical, obviamente realizadas antes de su amortización (López Palomo, 1981b: 251-252, Lám. 4). Sus dimensiones, a las que hay que añadir su mayor calidad artística respecto al resto de las piezas similares conocidas, ha hecho pensar que fueran los ojos de un simulacro de la diosa, quizás de madera (Almagro-Gorbea y Moneo, 2000: 24). Fuera así o un exvoto, estamos de acuerdo en que la representación alude a la divinidad y no al devoto que imploraría o agradecería la curación de un órgano enfermo (Horn, 2005: 108). La sobre dimensión de los ojos o de las orejas como forma de destacar cualidades divinas -el poder de verlo y oírlo todo- es bien conocida en la iconografía púnica y con ella entroncan sin duda los ejemplos que nos ofrecen algunos relieves del santuario de Las Atalayuelas (Rueda, 2011: Fig. 93: AT17 y AT19). Por otra parte, el creciente y el disco nos dicen que es una deidad celeste, lunar y astral. Uno y otro son símbolos religiosos de origen Próximo Oriental que tuvieron gran difusión en el mundo púnico a partir del siglo VI a.C. Hay cierto desacuerdo sobre si el globo que acompaña al creciente representa al sol o al planeta Venus (Chaves y Marín, 1982: 659; Cutroni Tusa, 2001: 77), pero su diminuto tamaño en la placa oculada de Alhonoz nos lleva a pronunciarnos a favor de la segunda opción, al menos en este caso. El creciente, con o sin disco y en distintas posiciones, es un motivo muy frecuente en las acuñaciones púnicas, tanto norteafricanas como hispanas. En concreto, la variante con puntas hacia abajo y disco en el centro la encontramos en monedas de Asido, Baílo, Carteia y Malaca (Chaves y Marín, 1982: fig. 1).

\footnotetext{
${ }^{17}$ Es una idea que agradezco al profesor J. Ma Luzón, así como algunos documentos literarios y gráficos que permiten contrastarla. En una hydria griega del Metropolitan Museum, fechada por su inscripción funeraria en el 213 a.C. (www.metmuseum.org/collections, 90.9.29), el punto en el que se cruzan las bandas de la inmortalidad, que son el motivo principal, lo ocupa una roseta de cuatro pétalos, equivalente al signo estelar con cuatro puntas de Alhonoz. Arriba y debajo de ella, hay otros astros que siguen un
}

Los esteliformes, de cuatro, seis y ocho puntas, pintados sobre muchos de los vasos de menor tamaño reiteran el carácter astral de la diosa (Fig. 6 y 7). Son símbolos de larga tradición fenicio-púnica, que, una vez más, abundan en las amonedaciones hispanas, principalmente en las que acuñan en alfabeto púnico, sin que de momento se haya ahondado en el significado de las distintas variantes (Escacena, 2011: 177, Fig. 13). El motivo en aspa, que a veces se describe como cruz en los estudios de iconografía monetal (Chaves y Marín, 1982: 666, v. g., Lám. $76,9)$, podría tener un carácter polisémico, por otra parte algo normal en los símbolos, y recalcaría el aspecto inmortal - eterno - de la diosa implícito en su propia naturaleza celeste ${ }^{17}$. Paralelamente, al expresar el carácter astral, estos motivos, al igual que el creciente, aluden también a la faceta agrícola y fecundadora de la divinidad (Chaves y Marín, 1982: 670) ${ }^{18}$, evocada asimismo en las representaciones de vegetales y de aves (Fig. 9). Unas y otras se conocen en la iconografía religiosa peninsular desde época orientalizante. Palmas, ramas o espigas, además de motivos astrales, encontramos sobre cerámica funeraria en fechas de los siglos VI-V a.C. (Schubart y Maass-Lindemann, 1995: v. g. Figs. 30: f, y 19: 290, respectivamente), y como los esteliformes, son un motivo muy frecuente en la iconografía de la amonedación hispana, principalmente en las tierras del interior del Guadalquivir. En cuanto a las aves, son un conocido atributo de las deidades femeninas propiciadoras de la fecundidad en el Mediterráneo antiguo, aunque no siempre tienen el mismo significado (Olmos y Tortosa, 2010). Finalmente, a la relación de la diosa con la tierra, a su naturaleza ctónica, podría responder también el hecho de colocar boca abajo la cerámica en el depósito sagrado (Aström, 1987; Domínguez Monedero 1995: 49).

esquema de representación mediante puntos del que existen paralelos en todo el Mediterráneo y en la misma Península Ibérica (Belén y Escacena, 2002: 175, Fig. 9).

18 A este respecto nos parece sugestiva la hipótesis que relaciona con el ciclo agrícola la representación del creciente lunar en distintas fases (Cutroni Tusa, 2001), como lo encontramos en las monedas de Sexs (Chaves y Marín, 1982: Fig. 1). 


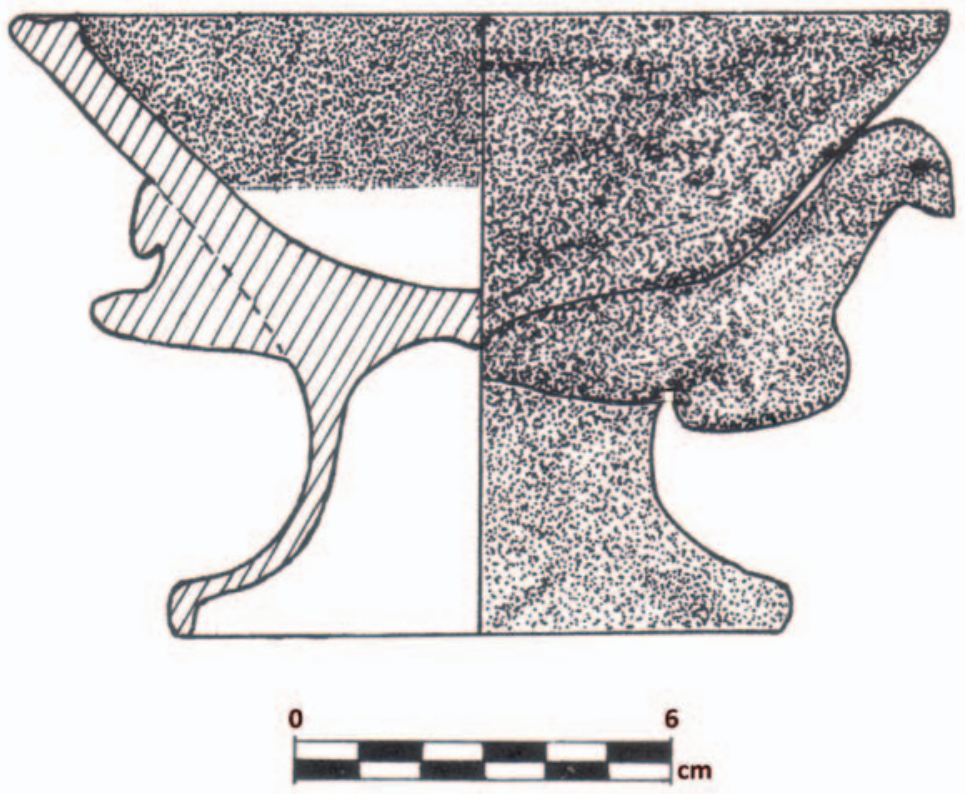

Figura 9. Alhonoz, 1977. Copa con aves del estrato II. (López Palomo, 1981a: Fig. 23).

Los datos comentados dan el perfil de una divinidad urania y ctonia, patrona del oppidum $\mathrm{y}$ de su territorio, guerrera y benefactora, atenta a las plegarias de sus fieles. La raigambre púnica del sistema simbólico a través del cual se manifiesta su personalidad, redunda en un fenómeno repetidamente constatado en la religiosidad de la Turdetania de los primeros siglos del dominio romano, tanto a través de la iconografía monetal como de los espacios y prácticas de culto (Rueda, 2011: 277-278). El alfabeto púnico de las monedas de Urso y Sacili ${ }^{19}$, es una prueba inequívoca de la presencia física de comunidades púnicas en el Medio y Alto Guadalquivir, por otra parte atestiguada por otras fuentes arqueológicas y literarias, a la vez que certifica la complejidad poblacional de la sociedad turdetana (García Fernández, 2007). Sin embargo, la cultura híbrida que resultó tras siglos de interacción (Ferrer y Álvarez, 2009: 225) no tiene una lectura fácil en términos étnicos. Si en Torreparedones podemos pensar en una comunidad semita que veneraba a la Tinnit púnica bajo el nombre romano de Dea Caelestis

19 Identificado recientemente (Mora, 2012: 107). Las cecas púnicas de la Turdetania meridional, mejor conocidas, han sido estudiadas, entre otros, por García y Bellido, 2000: 141-142
(Marín, 1993, Fernández Castro y Cunliffe, 2002: 70-79), en el santuario de Las Atalayuelas, que comparte no pocos rasgos con aquél, se daba culto a una divinidad indígena llamada Betatun (Rueda, 2011: 240-241). El apelativo Martialis que identifica a la diosa Juno como patrona de la Sacili romana, encubre posiblemente un culto prerromano a una Tinnit de carácter guerrero y, a la vez, protectora de los campos (La Rocca, 1999: 836-837) ${ }^{20}$, como la anónima diosa de Alhonoz que alguien pudo asimilar a esa otra Iuno Sospita o Caprotina, poliada, guerrera y salvadora, del reverso del denario de C(aius)RENI(us) (Ibidem: 819-822). Es probable que el oppidum de Alhonoz fuera una de las muchas ciudades turdetanas con población mixta de las que habla Estrabón (III, 2, 13). Lo cierto es que en la nueva situación social y política impuesta, el culto a la patrona, presentado con un lenguaje simbólico de clara raíz púnica, debió ser el principal referente de su identidad cívica, de su pasado y de su confrontación cultural con el mundo romano.
20 Sobre la asimilación de Astarté y Tinnit con la Juno romana, vid. Cadotte, 2007: 91-105 


\section{Bibliografía}

ALMAGRO-GORBEA, M. y DOMÍNGUEZ DE LA CONCHA, A. (1988-89): "El palacio de Cancho Roano y sus paralelos arquitectónicos y funcionales". Zephyrvs XLI-XLII, 339-382.

ALMAGRO-GORBEA, M. y MONEO, T. (2000): Santuarios urbanos en el mundo ibérico. Madrid.

ARANEGUI, C. 1997: "La favissa del santuario urbano de Edeta-Líria (Valencia)". Quaderns de Prehistòria i Arqueologia de Castelló 18, 103113.

ASTRÖM, P. (1987): "Inverted Vases in Old World Religion”. Journal of Prehistoric Religion I, 7-16.

BEIRÂO, C. de M.; DA SILVA, C.T.; SOARES, J.; GOMES, M.V. y GOMES, R.V. (1985): "Depósito votivo da II Idade do Ferro de Garvâo. Notícia da primeira campanha de escavaçôes".O Arqueólogo Português série IV, 3, 45-136.

BELÉN, M. y ESCACENA, J. L. (2002): "La imagen de la divinidad en el mundo tartésico". Ex Oriente Lux: Las religiones orientales antiguas en la Península Ibérica (E. Ferrer, ed.): 159-184. Sevilla.

BELTRÁN, M. (1990): Guía de la cerámica romana. Zaragoza.

BENDALA, M. (1994): "El influjo Cartaginés en el interior de Andalucía". Cartago, Gadir, Ebusus y la influencia Púnica en los Territorios Hispanos. VIII Jornadas de Arqueología Fenicio-Púnica, 59-74. Ibiza.

BLÁNQUEZ, J. (1996): "Lugares de culto en el mundo ibérico. (Nuevas propuestas interpretativas de espacios singulares en el sureste meseteño)". REIb 2, 147-172.

BLECH, M. (1982): "Minerva in der republicanischen Hispania". Feschrift für Ulrich Hausmann (B. von Freytag, D. Mannsperger y F. Prayon, eds.): 136-145. Tübingen.

BRONCANO, S. 1989: El depósito votivo ibérico de El Amarejo. Bonete (Albacete). Excavaciones Arqueológicas en España 156. Madrid.

CADOTTE, A. (2007): La romanisation des Dieux. L'interpretatio romana en Afrique du Nord sous le haut-Empire. Leiden-Boston.

CHAVES, F. y MARÍN, Mª C. (1992): “El elemento religioso en la amonedación hispánica antigua", Actes $d u$ gème Congrès International de Numismatique (T. Hackens y R. Weiller, eds.): 657-671. Louvain-La-Neuve.
CHAVES, F. y MARÍN, Ma C. (2004): "Las cabezas galeadas en la amonedación hispana". La Tradizione Iconica Come Fonte Storica: Il Ruolo Della Numismatica Negli Studi di Iconografia (M. Caccamo Caltabiano, D. Castrizio y M.A. Puglisi, eds.): 351-384. Messina.

CUTRONI TUSA, A. (2001): 'Simboli astrali nella monetazione punica'. Zona Archeologica. Festschrift für Hans Peter Isler zum 60. Geburtstag (S. Buzzi et al., eds.): 78-89. Bonn.

ESCACENA, J. L. (1987a): "El poblamiento ibérico en el Bajo Guadalquivir". Iberos. Actas de las Primeras Jornadas sobre el Mundo Ibérico / Jaén, 1985 (A. Ruiz y M. Molinos, eds.): 273298. Jaén.

ESCACENA, J. L. (1987b): Cerámicas a torno pintadas andaluzas de la II Edad del Hierro. Tesis Doctoral microfilmada. Cádiz.

ESCACENA, J. L. (1992): "Cerámicas votivas de Alhonoz". Andalucía y el Mediterráneo (F. Amores, coord.): 118-119. Almería.

ESCACENA, J. L. (2011): "Variación identitaria entre los orientales de Tartessos. Reflexiones desde el antiesencialismo darwinista". Fenicios en Tartessos: nuevas perspectivas (M. Álvarez, ed.). BAR International Series 2245: 161-192. Oxford.

DE LA BANDERA, Ma L. y FERRER, E. (1995): "Reconstrucción del ajuar de una tumba de Cástulo: ¿indicios de mestizaje?”. Kolaios 4, 53-65.

DOMÍNGUEZ MONEDERO, A. J. (1995): “Religión, rito y ritual durante la protohistoria peninsular. El fenómeno religioso en la Cultura Ibérica". Ritual, Rites and Religion in Prehistory. IIIrd Deya International Conference of Prehistory, (W. H. Waldren, J. A. Ensenyat y R. C. Kennard, eds.). Tempus Reparatum. BAR International Series 611: 21-91. Oxford.

FERNÁNDEZ CASTRO, M ${ }^{\mathrm{a}}$ C. y CUNLIFFE, B. W. (2002): El yacimiento y el santuario de Torreparedones. Un lugar arqueológico preferente en la campiña de Córdoba. BAR International Series 1030. Oxford.

FERRER, E. y ÁLVAREZ, M. (2009): “Comunidad cívica e identidad en la Iberia púnica". Identidades, culturas y territorios en la Andalucía prerromana (F. Wulff y M. Álvarez, eds.): 205235. Málaga.

FERRER, E. y GARCÍA FERNÁNDEZ, F. J. (2008): "Cerámica turdetana". Cerámicas hispanorromanas. Un estado de la cuestión (D. Bernal y A. Ribera, eds.): 201-219. Cádiz. 
GARBATI, G. (2012) : "Favissa”. Dizionario Enciclopedico della Civiltà Fenicia. Roma. (www.decf-cnr.org).

GARCÍA-BELLIDO, Ma P. (1990): “Iconografía fenicio-púnica en la moneda romana-republicana de la Bética”. I Coloquio Internacional sobre religiones Prehistóricas de la Península Ibérica. Zephyrus XLIII, 371-383.

GARCÍA-BELLIDO, M ${ }^{\mathrm{a}}$ P. (2000): “La relación económica entre la minería y la moneda púnicas en Iberia". Los cartagineses y la monetización del Mediterráneo occidental ( $\mathrm{M}^{\mathrm{a}} \mathrm{P}$. García-Bellido y L. Callegarin, coords.). ANEJOS AEspA XXII: 127-144. Madrid.

HORN, F. (2005): “"Le visible et l'invisible”. Réflexions sur l'interprétation des plaquettes oculaires métalliques de la Péninsule Ibérique préromaine». AespA 78, 97-117.

IZQUIERDO, I. (2003): "La ofrenda sagrada del vaso en la cultura Ibérica”. Zephyrus LVI, 117-135.

JIMÉNEZ ÁVILA, J. (2002): La Toréutica orientalizante en la Península Ibérica. Madrid.

LA ROCCA, E. (1999); "Iuno”. LIMC V, I: 814-856. Zürich-München.

LÓPEZ PALOMO, L. A. (1979): La cultura ibérica del Valle Medio del Genil. Córdoba.

LÓPEZ PALOMO, L. A. (1980): “Alhonoz: ciudad perdida en la Protohistoria Andaluza". Revista de Arqueología 26, 16-23.

LÓPEZ PALOMO, L. A. (1981a): "Alhonoz. Excavaciones de 1973 a 1978". Noticiario Arqueológico Hispánico 11, 33-189.

LÓPEZ PALOMO, L. A. (1981b): “Bronces y plata tartésicos de Alhonoz y su hinterland". Zephyrus XXXII-XXXIII, 245-263.

LÓPEZ PALOMO, L. A. (1999): El Poblamiento Protohistórico en el Valle Medio del Genil. Écija.

LÓPEZ PALOMO, L. A. (2002): “Alhonoz treinta años después (Precisiones cronológicas)". Actas del III Congreso de Historia de Andalucía: 85119. Córdoba.

MARÍN, Ma C. (1993): "Dea Caelestis en la epigrafía hispana". II Congresso Peninsular de Historia Antiga: 825-845. Coimbra.

MARÍN, Ma C. (2010): "Santuarios prerromanos de la costa atlántica andaluza". Debate en torno a la religiosidad protohistórica. Anejos de AEspA LV (T. Tortosa y S. Celestino, eds.): 125-140. Madrid.
MONEO, T. (2003): Religio Iberica. Santuarios, ritos $y$ divinidades (siglos VII-I A. C.). Madrid.

MORA, B. (2012): "Divinidades poliadas en las amonedaciones de tradición fenicio-púnica del sur de la península Ibérica". Déus i mites de l'antiguitat. L'evidència de la moneda d'Hispania: 106-109. Barcelona.

MORENA, J. A. (1989): "Relieve ibérico de Torreparedones (Córdoba)". Actas del Simposio Internacional sobre Urso (Osuna). Estudios sobre Urso. Colonia Iulia Genetiva (J. González, ed.): 335-343. Sevilla.

MORENA, J. A (2011): "Una nueva visión del santuario periurbano de Torreparedones (Baena, Córdoba)". ¿Hombres o dioses? Una nueva mirada a la escultura del mundo ibérico (J. Blánquez, ed.): 237-255. Madrid.

MORET, P. (1996): Les fortifications ibériques de la fin de l'âge du Bronze à la conquête romaine. Collection de la Casa de Velázquez 56. Madrid.

NIVEAU DE VILLEDARY, A. M (2003): Cerámicas gaditanas “tipo Kuass”. Madrid.

OLMOS, R. (2000-2001): "Diosas y animales que amamantan: la transmisión de la vida en la iconografía ibérica". Zephyrus LIII-LIV, 353-378.

OLMOS, R. y TORTOSA, T. (2020): “Aves, diosas y mujeres". La Dama de Baza. Un viaje femenino al más allá (T. Chapa e I. Izquierdo, coords.): 243275. Madrid.

PEREIRA, J. (1988): La cerámica pintada a torno en Andalucía entre los siglos VI y III a. d. C. Cuenca del Guadalquivir. Madrid.

PRINCIPAL, J. (2005): "Las cerámicas del círculo de la Campaniense B". Introducción al estudio de la cerámica romana. Una breve guía de referencia (M. Roca y M ${ }^{\mathrm{a}}$ I. Fernández, coords.): 47-61. Málaga.

PUYA, M. y CAMPOS, J. M. (1983): "Sevilla en el I Milenio: la protohistoria". Sevilla y su provincia (M. A. Vázquez y A. Mª Flores, eds.), II: 67-114. Sevilla.

RODRÍGUEZ NEILA, J. F. (1988): Historia de Córdoba 1. Del amanecer prehistórico al ocaso visigodo. Córdoba.

RUEDA, C. (2011): Territorio, culto e iconografía en los santuarios iberos del Alto Guadalquivir (ss. IV a.n.e.-I d.n.e). Jaén.

SCHUBART, H. y MAASS-LINDEMANN, G. (1995): "Las excavaciones en la Necrópolis de Jardín (Vélez-Málaga, Málaga)". Cuadernos de Arqueología Mediterránea 1, 57-64. 
SEGARRA, D. (2006): “Archeologia e storia delle religioni: il caso della miniaturizzazione di oggetti destinati alla sfera extra-umana". "Archeologia e religione" Atti del I Colloquio del "Gruppo di contatto per lo studio delle religioni mediterranee" (Storia delle religioni II) (M. Rocchi y P. Xella, coords.): 109-120.Verona.

VAQUERIZO, D. (1999): La Cultura Ibérica en Córdoba. Un ensayo de sintesis. Córdoba.
VENTURA, J. J. (2001): “Cerámicas de barniz negro en Carmona". Carmona romana (A. Caballos, ed.): 321-337. Carmona.

VIVAR, G. (2005): "La Cerámica Campaniense A". Introducción al estudio de la cerámica romana. Una breve guía de referencia (M. Roca y $\mathrm{M}^{\mathrm{a}} \mathrm{I}$. Fernández, coords.): 23-45. Málaga. 